Tropical Journal of Pharmaceutical Research September 2020; 19 (9): 1963-1968

ISSN: $1596-5996$ (print); 1596-9827 (electronic)

(C) Pharmacotherapy Group, Faculty of Pharmacy, University of Benin, Benin City, 300001 Nigeria.

\title{
Effect of berberine on hyperandrogenemia, ovulation dysfunction and inflammation in a mouse model of polycystic ovary syndrome
}

\author{
Kena Lu*, Hanmei Lin \\ Department of Gynecology, The First Affiliated Hospital of Guangxi University of Chinese Medicine, Nanning, PR China
}

*For correspondence: Email: cgibi7@163.com

Sent for review: 5 June 2020

Revised accepted: 31 August 2020

\begin{abstract}
Purpose: To study the effect of berberine (BBR) on hyperandrogenemia (HA), ovulation dysfunction and inflammation in a mouse model of polycystic ovary syndrome (PCOS).

Methods: Forty-five female Kunming mice were randomly divided into control group (9 mice), and mice injected with dehydroepiandrosterone $(n=36)$ for establishment of PCOS model. The PCOS mice were randomly divided into model group, low-dose BBR $(0.25 \mathrm{~g} / \mathrm{kg})$, medium-dose BBR $(0.5 \mathrm{~g} / \mathrm{kg})$ and highdose $(1.0 \mathrm{~g} / \mathrm{kg})$ groups, with 9 mice in each group. Changes in ovarian morphology were monitored, and sex hormone levels i.e. testosterone $(T)$ and luteinizing hormone $(L H))$, and inflammatory factors were determined.

Results: The model group levels of $T$ and $\mathrm{LH}$ were significantly higher than those of the blank control group ( $p<0.05)$, but $T$ and $L H$ levels were significantly lower in middle- and high-dose BBR groups than in the model mice. There were marked increases in IL-6 and TNF- $\alpha$ levels in model mice, when compared to blank control mice, but reduced in the mice treated at the 3 doses of $B B R$, relative to model mice $(p<0.05)$. In contrast, the number of follicles was higher at each stage of development in mice for each BBR dose than in the model mice, with increase in corpus luteum.

Conclusion: Berberine lowers the weight of PCOS mice, mitigates hyperandrogenemia and inflammatory state, and enhances recovery of ovulation. However, there is need for further studies on its clinic applicability.

Keywords: Berberine, Polycystic ovary syndrome, Hyperandrogenemia, Ovulation dysfunction, Inflammatory
\end{abstract}

\begin{abstract}
This is an Open Access article that uses a fund-ing model which does not charge readers or their institutions for access and distributed under the terms of the Creative Commons Attribution License (http://creativecommons.org/licenses/by/4.0) and the Budapest Open Access Initiative (http://www.budapestopenaccessinitiative.org/read), which permit unrestricted use, distribution, and reproduction in any medium, provided the original work is properly credited.

Tropical Journal of Pharmaceutical Research is indexed by Science Citation Index (SciSearch), Scopus, International Pharmaceutical Abstract, Chemical Abstracts, Embase, Index Copernicus, EBSCO, African Index Medicus, JournalSeek, Journal Citation Reports/Science Edition, Directory of Open Access Journals (DOAJ), African Journal Online, Bioline International, Open-J-Gate and Pharmacy Abstracts
\end{abstract}

\section{INTRODUCTION}

Polycystic ovary syndrome (PCOS) is a common disease in women of child-bearing age, with an incidence of $10 \%$. It is also caused by endocrine and metabolic abnormalities, mainly manifested as hyperandrogenism (HA), ovulation dysfunction, irregular menstrual cycle and infertility, and the associated complications may lead to type 2 diabetes [1,2]. At present, studies on the etiology of PCOS are based mainly on genetic and non-genetic theories of PCOS. While the genetic theory suggests that PCOS is influenced by family history, the non-heritage 
theory posits that uterine hormonal status during pregnancy has a great influence on the endocrine status of an individual in adulthood $[3,4]$. It has been shown that in 2014 , the number of obese people in China ranked first in the world, while from 1975 to 2014, the proportion of obese women in the world increased from 2.5 to $12.4 \%[5]$.

Research has shown that overweight or obesity aggravates metabolic abnormalities and reproductive disorders in PCOS patients [6]. The treatment of PCOS is usually individualized, based on the patient's condition. Nonetheless, the disease is effectively alleviated through prevention and treatment of obesity. Polycystic ovary syndrome (PCOS) should be treated for a long duration, and followed up, in order to meet the needs of patients. Patients with PCOS usually experience chronic inflammation: serum levels of IL-6 and TNF- $\alpha$ are significantly increased, and the levels of inflammatory mediators are positively correlated with the patient's condition [7]. It has been reported that sex hormones affect the distribution of human adipose tissue; the balance between androgens and estrogens influences gender dimorphism [8].

Berberine (BBR), a bioactive component of Coptis chinensis, possesses anti-tumor and antiobesity properties. It has been reported that BBR regulates menstrual cycle, and mitigates insulin resistance and androgen levels [9]. In the present study, the influence of BBR on HA, ovulation dysfunction and inflammation was investigated in a mouse model of PCOS.

\section{EXPERIMENTAL}

\section{Animals}

Female Kunming mice (45) aged 3 - 4 weeks were purchased from Beijing Huafukang Company (production batch No.: SCXK; Beijing 2018-0020). The mice were maintained on SPF for 1 week. This research received approval from the Animal Ethical Committee of our institution (approval no. 20198726) and was conducted in line with the "Principles of Laboratory Animal Care" [10].

\section{Main reagents and instruments used}

Berberine (BB) was purchased from Dexter Biotechnology Co. Ltd.; paraformaldehyde was bought from Shanghai Guchen Biotechnology Co. Ltd., while general development powder was purchased from Beijing Huaxing Konuo Biotechnology Co. Ltd. Acid fixing powder was purchased from Huaxing Konuo Co. Ltd.; extremely sensitive ELC Chemiluminescence kit was obtained from Shanghai Shuojia Biotechnology Co. Ltd., while ELISA kits for luteinizing hormone, TNF- $\alpha$, IL-6 and testosterone were purchased from Jiangsu Baolai Biology Technology Co. Ltd. Methanol was a product of Qingdao Jielong Chemical Co. Ltd.

Electrophoresis instrument was purchased from Shanghai Jiapeng Technology Co. Ltd. Electronic balance was bought from Beijing Xijie Balance Instrument Co. Ltd. Enzyme labeling instrument was supplied by Meigu Molecular Instrument Co. Ltd. Electrothermal thermostatic water bath was purchased from Tianjin Taist Instrument Co. Ltd. Electrothermal thermostatic vacuum drying oven was product of Shanghai Lanhao Instrument Equipment Co. Ltd. Highspeed, low-temperature centrifuge was purchased from Shanghai Luxianyi Centrifugal Machine Instrument Co. Ltd. Shaker was produced by Henan Hongxing Mining Machinery Co. Ltd. Microinjector was obtained from Hangzhou Junsheng Science Equipment Co. Ltd., while pipettes were products of Iroda Instrument Co. Ltd.

Two mice groups were used: blank control ( 9 mice) and model mice (36 mice). Mice in the blank control received sesame oil $(0.09 \mathrm{~m})$ and $95 \%$ ethanol $(0.01 \mathrm{~mL})$ once a day, while model mice received DHEA $(6 \mathrm{mg} / 100 \mathrm{~g})$ for 20 consecutive days (for induction of PCOS). Following successful establishment of PCOS, the mice were divided into model group, low-dose $\mathrm{BBR}$, medium-dose BBR and high-dose BBR $(0.25,0.5$ and $1.0 \mathrm{~g} / \mathrm{kg}$, respectively), using the random number table method. Each group had 9 mice. Mice in the blank control and model groups were given equivalent volumes of saline in place of BBR by gavage, while BBR-treated mice received BBR at doses of 0.25 (low), 0.5 (medium) and $1.0 \mathrm{~g} / \mathrm{kg}$ (high) via gavage for 14 consecutive days. The rats were weighed every 5 days.

After 14 days, all mice were anesthetized. Peripheral blood samples were taken and centrifuged, and the resultant sera were kept in an ultra-low temperature refrigerator. The mice ovaries were excised, fixed in $4 \%$ POM, and the embedded sections were made into specimens. Changes in ovarian histomorphology were determined. The ovary sections were processed for light microscopy and subjected to staining with hematoxylin and eosin (H\&E), observed under the microscope, and photographed.

\section{Determination of cytokines}

Trop J Pharm Res, September 2020; 19(9): 1964 
Serum levels of IL-6 and TNF- $\alpha$ were assayed using ELISA kits in line with the manufacturer's protocol (Baolai Bio, Jiangsu, China). Enzymelinked immunosorbent assay was used to detect the serum IL-6 and TNF- $\alpha$ levels of mice in each group. Mouse serum $(10 \mu \mathrm{L})$ diluted 1:5 was put in 96-well plate containing $50 \mu \mathrm{L}$ of appropriate standard and $40 \mu \mathrm{L}$ of diluent. Test and control wells were set up simultaneously for each sample. Then, $100 \mu \mathrm{L}$ of enzyme-labeled reagent was added to each well, while the blank wells were left untreated. The wells were then sealed and incubated at room temperature for $2 \mathrm{~h}$, after which the contents of each well was diluted 20 times. The medium in each well was discarded, followed by rinsing thrice with washing solution, and blotting with absorbent paper. Thereafter, $50 \mu \mathrm{L}$ of developer A was added to each well, followed by further addition of $50 \mu \mathrm{L}$ of color developer, with gentle agitation to ensure mixing. The mixture was kept in the dark at room temperature for $15 \mathrm{~min}$, followed by addition of $50 \mu \mathrm{L}$ of stop solution to each well to stop the reaction. The optical density (OD) of each well was read at $450 \mathrm{~nm}$ in a microplate reader, against blank.

\section{Radioimmunoassay}

Radioimmunoassay was used to measure the levels of testosterone (T) and luteinizing hormone (LH) (Baolai Bio, Jiangsu, China). The sample was injected into a test tube along with appropriate antibody, and $0.2 \mathrm{~mL}$ of distilled water was added. When fully dissolved, the separating agent was added, and the free antigen and the antigen-antibody complex were separated after precipitation using a centrifuge. Then, $20 \mu \mathrm{L}$ was put in a polystyrene test tube containing $100 \mu \mathrm{L}$ of DNA quantification buffer and IDNA solution. After thorough mixing, the solution was incubated at $37^{\circ} \mathrm{C}$ for $1 \mathrm{~h}$, followed by addition of $1000 \mu \mathrm{L}$ of DNA quantitative separating agent, shaking and incubation at $25^{\circ} \mathrm{C}$ for $15 \mathrm{~min}$. Then, the mixture was subjected to centrifugation, and the supernatant was discarded. Then, the radioactivity count (cmp) value of each sediment was determined, and the results were analyzed using computer immuneradiation method to automatically process the calculation of results with four-parameter regression. All samples were tested in the same batch to prevent inter-batch errors.

\section{Statistics}

Data are expressed as mean \pm standard deviation (SD). Statistical analysis was carried out by independent sample $t$-test. All data analyses were done using SPSS ver. 23.0 software. Statistical significance of difference was assumed at $p<0.05$.

\section{RESULTS}

\section{Effect of BBR on weight of mice with polycystic ovary syndrome}

As shown in Table 1, model mice weighed markedly more than mice in blank control mice, but mice given BBR at middle and high doses weighed significantly lower than model mice $(p<$ 0.05). The body weights of low-dose BBR mice and blank control mice were comparable.

Table 1: Effect of BBR on body weight of PCOS mice (mean $\pm \mathrm{SD}, \mathrm{n}=9$ )

\begin{tabular}{ll}
\hline Group & Body weight $\mathbf{( g )}$ \\
\hline Blank control & $18.27 \pm 1.17$ \\
Model & $19.83 \pm 1.72^{\mathrm{a}}$ \\
Low-dose BBR & $19.21 \pm 1.10$ \\
Medium-dose BBR & $17.92 \pm 1.53^{\mathrm{b}}$ \\
High-dose BBR & $17.68 \pm 1.27^{\mathrm{b}}$ \\
\hline $\begin{array}{l}\text { Values are mean } \pm \text { SD. }{ }^{\mathrm{a}} P<0.05, \text { vs blank; }{ }^{\mathrm{b}} p<0.05 \\
\text { vs model mice }\end{array}$
\end{tabular}

\section{Effect of BB on sex hormone levels in PCOS mice}

The levels of T and LH were markedly elevated in model mice, relative to blank control mice. However, $\mathrm{T}$ and $\mathrm{LH}$ levels were significantly reduced in mice fed middle and high BBR doses, relative to model mice $(p<0.05)$. No significant differences in $\mathrm{T}$ and $\mathrm{LH}$ levels were seen between low-dose BBR and the blank control mice $(p>0.05)$. These data are presented in Table 2.

Table 2: Effect of BB on sex hormone levels in PCOS mice (mean $\pm S D, n=9$ )

\begin{tabular}{lcc}
\hline Group & $\mathbf{T}(\mathbf{n g} / \mathbf{m L})$ & $\mathbf{L H}(\mathbf{m l U} / \mathbf{m L})$ \\
\hline Blank control & $11.23 \pm 0.88$ & $25.83 \pm 1.92$ \\
Model & $13.21 \pm 0.79$ & $31.23 \pm 1.77^{\mathrm{a}}$ \\
Low-dose BBR & $12.24 \pm 1.97$ & $30.01 \pm 1.43$ \\
Medium-dose BBR & $12.21 \pm 0.89$ & $26.25 \pm 2.83^{\mathrm{b}}$ \\
High-dose BBR & $12.09 \pm 0.34$ & $24.43 \pm 1.68^{\mathrm{b}}$ \\
\hline
\end{tabular}

Results are mean \pm SD. ${ }^{a} P<0.05$, vs blank; ${ }^{b} p<0.05$, vs model

\section{Effect of BB on inflammatory factors in PCOS mice}

Table 3 reveals that concentrations of TNF- $\alpha$ and IL-6 were markedly raised in model mice, relative to blank control mice, and but they were markedly reduced in all BBR-treated mice, relative to model mice $(p<0.05)$.

Trop J Pharm Res, September 2020; 19(9): 1965 
Table 3: Effect of BB on inflammatory factors in PCOS mice (mean $\pm S D, n=9$ )

\begin{tabular}{lcc}
\hline Group & IL-6 $(\mathbf{p g} / \mathrm{mL})$ & TNF- $\alpha(\mathbf{p g} / \mathrm{mL})$ \\
\hline Blank control & $22.48 \pm 1.79$ & $278.69 \pm 46.31$ \\
Model & $33.08 \pm 5.03^{\mathrm{a}}$ & $368.31 \pm 50.21^{\mathrm{a}}$ \\
Low-dose BBR & $26.64 \pm 6.38^{\mathrm{b}}$ & $269.56 \pm 56.58^{\mathrm{b}}$ \\
Medium-dose BBR & $22.98 \pm 1.98^{\mathrm{b}}$ & $265.43 \pm 35.62^{\mathrm{b}}$ \\
High-dose BBR & $22.39 \pm 1.63^{\mathrm{b}}$ & $260.32 \pm 40.23^{\mathrm{b}}$ \\
\hline Results are presented as mean \pm SD. ${ }^{\mathrm{a}} P<0.05, \mathrm{vs}$ \\
blank; ${ }^{\mathrm{b}} p<0.05$, vs model
\end{tabular}

\section{Effect of BB on ovary morphology in PCOS mice}

Figure 1 shows that the follicles and corpus luteum of the blank control mice appeared lesionfree under the microscope. In contrast, the number of follicles in each stage of development in the model group was significantly reduced, and the corpus luteum was either reduced or completely absent. The number of follicles in each stage of development in each BBR dose group was significantly higher than that in the model group, and the corpus luteum was increased.

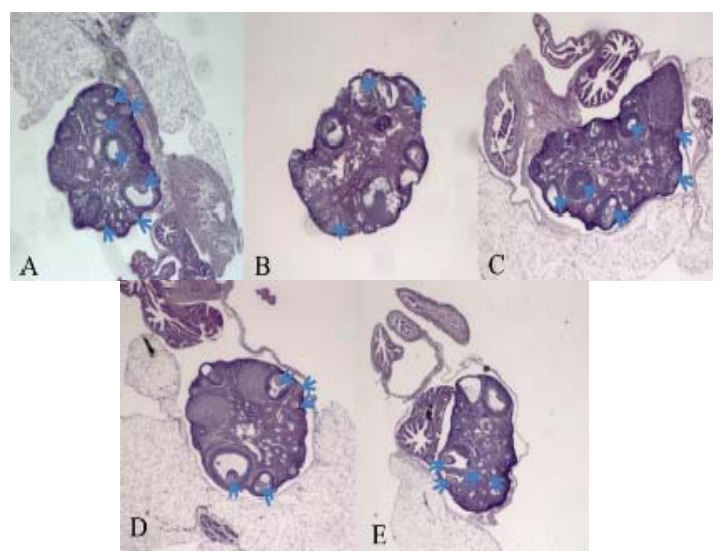

Figure 1: Effect of berberine on ovary of polycystic ovary syndrome mice. A: blank; B: model; C: low BBR; D: medium BBR; E: high BBR

\section{DISCUSSION}

A number of studies have confirmed that the high level of HA is responsible for the skin symptoms and reduced ovulation in PCOS. High HA level also leads to insulin resistance and imbalance in metabolic function in PCOS patients through abdominal and visceral obesity. Some scholars have suggested that over $28 \%$ of obese premenopausal women have high androgen levels, and suffer from PCOS, with prevalence of severe obesity as high as $50 \%$. However, not all obese women develop polycystic ovary, and not all polycystic ovary patients are obese. Studies have shown that abnormal metabolic function may persist in patients with PCOS after reduction in abdominal obesity, and that abdominal obesity can aggravate the risk of PCOS.

Obesity increases the risk of infertility and significantly enhances impaired glucose tolerance and the risk of type 2 diabetes which constitute the metabolic abnormalities in PCOS [11]. In obese patients with polycystic disease, it is important to adopt lifestyle changes such as reasonable diet and exercise, and maintenance of appropriate weight through $5-10 \%$ reduction in initial weight. The purpose of this study was to evolve a strategy for controlling body weight, reducing fat, improving clinical symptoms and minimizing complications in patients with PCOS. In this study, berberine was used to treat PCOS in mice. There was marked weight increase in model mice weight, relative to blank control, and the BBR-treated mice weighed less than model mice. These results suggest that the high-dose berberine effectively reduced the weight of PCOS mice.

Insulin resistance causes hyperinsulinemia and elevated androgen level, resulting in the associated clinical signs and symptoms [12]. Luteinizing hormone is closely associated with ovulation in menstrual cycle, and it functions in synergy with $\mathrm{FSH}$ to maintain the ovarian cycle [13]. In this study, the levels of T and LH were markedly raised in the model group, and their levels in the middle and high dose BBR group was significantly lower than those in the model group. These results suggest that BBR effectively regulated $\mathrm{HA}$ and ovulation in PCOS mice, and the impact was more marked at high dose level. It was also found that the ovarian morphology of mice in model mice was adversely changed, while that of mice in the BBR-treated groups was significantly improved.

Significant increases in the serum levels of hsCRP, IL- 6 and TNF- $\alpha$ in patients with PCOS have been reported [14]. In obese patients with PCOS, there are variations in the degree of fat cell hypertrophy and the expression of fat factor. These differences elevate pro-inflammatory factors, accelerate inflammatory reactions, and bring about insulin resistance in PCOS patients $[15,16]$. In addition, obesity influences the degree of inflammation in patients with PCOS $[17,18]$. The mouse model of PCOS used in this study was in a state of chronic inflammation, with significantly higher concentrations of IL- 6 and TNF- $\alpha$ than in the blank control. However, IL-6 and TNF - $\alpha$ levels in all BBR-treated mice were 
significantly lower than those in model mice. These results clearly demonstrate that BBR effectively reduced the inflammatory response in PCOS mice in a concentration-based fashion.

\section{CONCLUSION}

These findings suggest that BBR significantly reduces body weight and the degree of hyperandrogenemia and inflammatory reaction, and enhances the recovery of ovulation function in mice with PCOS. These may be used to promote ovulation recovery in women. However, there is need for prior clinical trials.

\section{DECLARATIONS}

\section{Conflict of interest}

No conflict of interest is associated with this work.

\section{Contribution of authors}

This study was done by the authors named in this article, and the authors accept all liabilities resulting from claims which relate to this article and its contents. The study was conceived and designed by Kena Lu; Kena Lu collected and analyzed the data while Kena Lu wrote the manuscript. All authors read and approved the manuscript for publication.

\section{Open Access}

This is an Open Access article that uses a funding model which does not charge readers or their institutions for access and distributed under the terms of the Creative Commons Attribution License (http://creativecommons.org/licenses/by/ 4.0) and the Budapest Open Access Initiative (http://www.budapestopenaccessinitiative.org/rea d), which permit unrestricted use, distribution, and reproduction in any medium, provided the original work is properly credited.

\section{REFERENCES}

1. Panico A, Messina G, Lupoli GA, Lupoli R, Cacciapuoti $M$, Moscatelli $F$, Esposito $T$, Villano I, Valenzano A, Monda V, et al. Quality of life in overweight (obese) and normal-weight women with polycystic ovary syndrome. Patient Prefer Adherence 2017; 11(3): 423-429.

2. Wang FF, Pan JX, Wu Y, Zhu YH, Hardiman PJ, Qu F. American, European, and Chinese practice guidelines or consensuses of polycystic ovary syndrome: a comparative analysis. J Zhejiang Univ Sci B 2018; 19(5): 354-363.
3. Jeanes YM, Reeves S. Metabolic consequences of obesity and insulin resistance in polycystic ovary syndrome: diagnostic and methodological challenges. Nutr Res Rev 2017; 30(1): 97-105.

4. Harris H, Jordan S, Risch H, Rossing MA, Goodman MT, Modugno F, Kjaer S, Schildkraut JM, Bandera EV, Wentzensen N, et al. Abstract 2293: Oligomenorrhea, polycystic ovary syndrome, and risk of ovarian cancer histotypes, evidence from the Ovarian Cancer Association Consortium. Cancer Res 2017; 77(2): 2293.

5. Feng $X, L u$ C, Na L, Zhao $Y$, Han QM, Wang XL, Wang $W$, Ma LP, Zhao XJ. Metabolomics biomarker analysis of threatened abortion in polycystic ovary syndrome: a clinical discovery study. Rsc Advances 2017; 7(83): 52923-52929.

6. Yuan $\mathrm{BC}$, Ma K, Zhang $\mathrm{CH}$, Yuan Y. Bushen Huoxue herbal medicine in subfertile women with polycystic ovary syndrome: a Meta-analysis. Zhongguo Zhong yao za zhi 2019; 44(6): 1080-1093.

7. Hassan G. Roles of IL-6 in Ocular Inflammation: A Review. Ocul Immunol Inflamm 2017; 26(1): 1-14.

8. Dadachanji R, Shaikh N, Mukherjee S. Genetic Variants Associated with Hyperandrogenemia in PCOS Pathophysiology. Genet Res Int 2018; 2018(2): 1-12.

9. Wang Y, Shou JW, Li XY, Zhao ZX, Fu J, He CY, Feng $R$, Ma $C$, Wen BY, Guo $F$, et al. Berberine-induced bioactive metabolites of the gut microbiota improve energy metabolism. Metabolism 2017; 70(1): 72-84.

10. World Health Organization. Principles of laboratory animal care. WHO Chron 1985; 39: 51-56.

11. Liu AL, Xie HJ, Xie HY, Liu J, Yin J, Hu JS, Peng CY. Association between fat mass and obesity associated (FTO) gene rs9939609 A/T polymorphism and polycystic ovary syndrome: a systematic review and meta-analysis. BMC Med Genet 2018; 18(1): 89.

12. Mishra JS, More AS, Hankins GDV, Kumar $S$. Hyperandrogenemia Reduces Endothelium-Derived Hyperpolarizing Factor-Mediated Relaxation in Mesenteric Artery of Female Rats. Biol Reprod 2017; 96(6): 1221-1230.

13. Andoni A, Razenshteyn I, Nosatzki NS. Society for Industrial and Applied Mathematics Proceedings of the Twenty-Eighth Annual ACM-SIAM Symposium on Discrete Algorithms Proceedings of the Twenty-Eighth Annual ACM-SIAM Symposium on Discrete Algorithms LSH Forest: Practical Algorithms Ma. 2016: 67-78.

14. Wu X, Tao P, Zhou Q, Li J, Yu Z, Wang X, Li J, Li C, Yan $M$, Zhu Z, et al. IL-6 secreted by cancer-associated fibroblasts promotes epithelial-mesenchymal transition and metastasis of gastric cancer via JAK2/STAT3 signaling pathway. Oncotarget 2017; 8(13): 20741 20750.

15. Barazzoni R, Deutz NEP, Biolo G, Bischoff S, Boirie $Y$, Cederholm T, Cuerda C, Delzenne N, Leon Sanz M, Ljungqvist $\mathrm{O}$, et al. Carbohydrates and insulin resistance in clinical nutrition: Recommendations from the ESPEN expert group. Clin Nutr 2017; 36(2): 355-363.

Trop J Pharm Res, September 2020; 19(9): 1967 
16. Hancerliogullari N, Yaman S, Tokmak A. Association of Serum Vitamin B12 Level and Insulin Resistance in Non-Obese Adolescent Girls with Polycystic Ovarian Syndrome. Acta Med Mediterr 2019; 35(1): 319-326.

17. Tang YL, Yu J, Zeng ZG, Liu Y, Liu JY, Xu JX. Circulating omentin-1 levels in women with polycystic ovary syndrome: a meta-analysis. Gynecol Endocrinol 2017; 33(3): 6-14.

18. Masrour MJ, Azad Z. A Comparison of The Effects of Human Chorionic Gonadotropin and Oxytocin on Ovulation in Pcos Patients From 2015 Until 2018. Acta Med Mediterr 2018; 34(6): 1757-1763. 